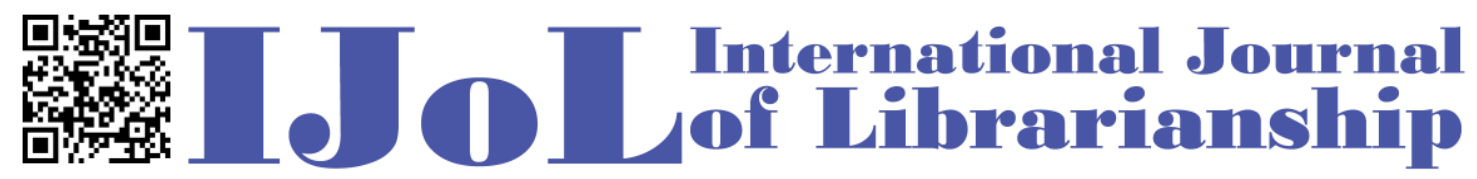

ISSN: 2474-3542 Journal homepage: http://journal.calaijol.org

\title{
The State of Library Makerspaces
}

Fangmin Wang, Weina Wang, Sally Wilson and Namir Ahmed

\begin{abstract}
:
In this paper, we describe the maker concept, movement and culture and its impact on and relationship with libraries. We provide a comprehensive review of library makerspaces in North America supported by several case studies. We intend this review to be used as a reference resource or tool for libraries planning to implement a new makerspace.
\end{abstract}

To cite this article:

Wang, F., Wang, W., Wilson, S., \& Ahmed, N. (2016). The state of library makerspaces. International Journal of Librarianship, 1(1), 2-16.

https://doi.org/10.23974/ijol.2016.vol1.1.12

To submit your article to this journal:

Go to http://ojs.calaijol.org/index.php/ijol/about/submissions 


\title{
The State of Library Makerspaces
}

\author{
Fangmin Wang, Weina Wang, Sally Wilson and Namir Ahmed \\ Ryerson University Library \& Archives, Toronto, Ontario, Canada
}

\begin{abstract}
In this paper, we describe the maker concept, movement and culture and its impact on and relationship with libraries. We provide a comprehensive review of library makerspaces in North America supported by several case studies. We intend this review to be used as a reference resource or tool for libraries planning to implement a new makerspace.
\end{abstract}

Keywords: makerspace, library, learning, digital, technologies, maker

\section{INTRODUCTION}

Makerspaces have been gaining momentum in libraries across North America. This trend reflects a paradigm shift; libraries are no longer built for bookshelves, but are creative and collaborative learning spaces designed for innovation and knowledge creation in the digital age. More and more public libraries, academic libraries, and even small libraries with limited staff and resources have started embracing the maker concept as a way to facilitate community engagement and empowerment. Although digital fabrication tools such as 3D printers and laser cutters are common in most library makerspaces, they do not define the space. Instead, it is the people and community that define and promote the maker culture.

\section{MAKER MOVEMENT}

Decades ago tinkering was considered a basic skill; however, the importance of this skill waned during the latter half of the twentieth century due to the rise of mass production, consumerism and the ubiquity of inexpensive goods. This trend has recently started to reverse. The creation of the web, the rise of hacker culture, and the availability of fabrication equipment has led to a resurgence in making things both digitally and physically. Dale Dougherty, who founded MAKE: Magazine in 2005, called this trend the "maker movement". To help readers of MAKE create a community and share knowledge, a public event called Maker Faire was launched a year later.

The definition of "makers" is broad. As Morin (2013) indicated, "You can think of makers as people creating physical things using the Web." According to Dougherty (2012), everyone is a maker. A maker can be someone who is gardening or someone who is building electronic toys. The rise of the maker movement stems from people's growing interest in engaging with physical objects and making things rather than just consuming them.

Three factors have helped build the maker movement. The first is the emergence of digital fabrication tools and software such as 3D printers, 3D scanners, laser cutters, Computer Assisted 
Design (CAD) software, etc. Such formerly expensive industrial tools have become personalized and available to individuals at a reasonable price. Second is the collaboration and innovation fostered by the Internet. Individual makers can now connect with others via the web to share ideas, learn technologies, create their communities, and work on projects together. The third and final element is the emergence of increasingly accessible and flexible factory services such as circuit manufacturing. Factories around the world can now take orders of any size and scale (Anderson, 2013).

Large companies have been getting involved in the maker movement too. Partnering with other companies and organizations, GE has launched a large-scale program called "GE Garages". This program provides space, digital manufacturing technology tools, workshops, and speaker sessions for individuals to learn new ways of prototyping and bringing their ideas to life (Barba, 2014).

The maker movement even got the White House's attention. President Barack Obama hosted the first-ever White House Maker Faire and proclaimed June 18, 2014 a National Day of Making. The event featured makers from students to entrepreneurs and innovators of all ages to spark creativity and encourage invention. The rise of the maker movement is now considered a huge opportunity for the country to revive its manufacturing industry (Kalil \& Miller, 2014).

Libraries and museums have also started embracing the maker movement. Sections of physical space have been turned into makerspaces and programs such as craft nights have been introduced into local communities. The growing shift from consumers of things to makers of things is going to have a transformative impact on the economy and future. This is a special moment in history, and the maker movement has only just begun (Morin, 2013).

\section{MAKER CULTURE}

The maker movement is not only a result of the democratization of digital technologies, but also a social movement that embraces every type of making and makers.

The maker movement links us to the past and transforms our views towards the future. In fact, it is a resurrection of some of our cultural values rooted in history. Today, makers from a wide range of ages and backgrounds create their own communities to share work and expertise. Maker culture offers individuals an exceptional social experience and helps unfold their full potential (Dougherty, 2013).

As Lay (2014) indicated, "The idea of 'maker culture' is that learning is best achieved through doing. It's the philosophy in which a person should create things using their hands or by using technology in a unique way". Maker culture has a strong focus on learning practical skills that can be used to turn creative ideas into physical realities.

In their Innovative Pedagogy 2013 report, Sharples et al. (2013, p. 33) stated, "the emerging 'maker culture' emphasizes informal, networked, peer-led, and shared learning motivated by fun and selffulfillment". Maker culture embraces the experimentation, invention, prototyping, and investigation of theory through self-directed practical work. It also encourages playful learning, knowledge sharing, creative thinking, social interaction, informal mentoring, and community collaboration and support.

Maker culture is considered an extension of Do It Yourself (DIY) culture with a strong technology focus, which fosters learning through using 3D printing, electronics, robotics, laser cutters, CNC (Computer Numerical Control) machines, etc. It also embraces interests in other traditional handson work and activities such as woodworking, metalworking, arts, and crafts. 


\section{MAKERSPACE DEFINED}

With the rise of maker movement and maker culture in the mid-2000s, a new type of space called a makerspace emerged. A makerspace is usually equipped with tools and technologies for people to get together to work on projects and learn practical skills from each other.

The Makerspace Playbook states that:

Makerspaces come in all shapes and sizes, but they all serve as a gathering point for tools, projects, mentors and expertise. A collection of tools does not define a Makerspace. Rather, we define it by what it enables: making. (2013, p. 1).

The main focus of a makerspace is learning and education. A makerspace enables learners to become producers of knowledge, rather than consumers of knowledge. It encourages collaborative, hands-on, project-based, and experiential learning. Makerspaces are usually created in a community environment, such as a community centre, library, business, university or K-12 school campus.

According to Educause (2013), "A makerspace is a physical location where people gather to share resources and knowledge, work on projects, network, and build. Makerspaces provide tools and working room in a community environment - a library, community center, private organization, or campus" (p. 1).

Makerspaces provide access to tools, education, and community. They are great facilities for experimenting with emerging technologies, project development, idea prototyping and selfdirected learning and discovery. Because of their hands-on learning nature, makerspaces have been quickly adopted in STEM education (science, technology, engineering, math). However, makerspaces are not only for scientific and technological activities. Increasingly, makerspaces serve the educational need in fields other than STEM. One good example is the Maker Lab in the Humanities at the University of Victoria.

The Library as Incubator Project (2012) defines makerspaces as, "collaborative learning environments where people come together to share materials and learn new skills", and concludes that, "makerspaces are not necessarily born out of a specific set of materials or spaces, but rather a mindset of community partnership, collaboration, and creation."

According to the 2014 New Media Consortium (NMC) Horizon report, there has been a growing interest in makerspaces as a result of the broad integration of creative processes and hands-on learning. Institutional leaders are increasingly viewing their students as creators rather than consumers; the expert panel expects this trend to peak within three to five years. In the 2015 and 2016 NMC Horizon reports, makerspaces were identified as one of the mid-term (2-3 years) key trends accelerating technology adoption in higher education.

\section{MAKERSPACES IN LIBRARIES}

Once aware of the characteristics of the makerspace, it is easy to see the link between a library and a makerspace. In the age of print, a library was perceived as a repository of information and knowledge. Today, the role of the library is changing because of the digital revolution.

Tashjian (2014) stated that "makerspaces are shifting educational and public organizations from being places where things are made or information is found to places where knowledge and ideas are developed and imagination and creativity are fostered." As an educational and public organization, the library is also undergoing this transformative shift. 
Bagley (2012) explained that "the maker movement in libraries is about teaching our patrons to think for themselves, to think creatively, and to look for do-it-yourself solutions before running off to the store." Therefore, a key role for a library makerspace is to help create creative people.

Tod Colegrove, director of the DeLaMare Library, said that a noisy library with a messy innovation workshop is actually a return to the library's origin (Rutkin, 2014). Learning from books is no longer the only way of acquiring knowledge. Modern society requires students to have highly specialized skills in technology. The best way to acquire this kind of knowledge and skills is through hands-on learning. The President of the American Library Association (ALA), Barbara Stripling, indicated that today's library should focus more on being a place of active learning than a repository (Rutkin, 2014). She also stated that information needs to be understood and applied, not just gathered.

The idea of making or makerspaces in libraries is not new. In 1873 the Gowanda Free Library started out as the Gowanda Ladies Social Society, where a group of local women would meet regularly to socialize, quilt, knit, sew, and discuss books they had read. In 1905, as the Head of the Children's Department at the Carnegie Library of Pittsburgh, Ms. Frances Jenkins Olcott, helped create home libraries in working-class houses. In these home libraries, the library staff would teach children about crafts such as sewing and basketry (Good \& Borman, 2013).

The Manitoba Crafts Museum and Library was created in 1933 for preserving the heritage of craft culture of Manitoba. The library was also used as a meeting place and provided resources for learning craft skills such as knitting and quilting (Manitoba Crafts Museum and Library, 2014).

On her "Words of Learning" blog, Fleming (2014) mentioned that "In 1960, the Nebraska Public Library Commission hosted a variety of special activities, including creative arts, which were organized by area groups."

The first tool lending library, Rebuilding Together Central Ohio Tool Library, was founded in 1976 in the City of Columbus, Ohio. Today, this unique tool library is open to the people of Franklin County, lending out 200 varieties and close to 4,500 tools. The community can borrow tools and access a variety of informative resources about making (Rebuilding Together Central Ohio, 2014).

Historically, libraries have encouraged life-long learning through their collections and programs. This, combined with the revived interest in making, has led to the emergence of a new type of library space, one equipped with new digital tools such as 3D printers and laser cutters. The Fayetteville Free Library, the New York Public Library, the Westport Public Library in Connecticut, the Chicago Public Library, and the DeLaMare Science and Engineering Library at the University of Nevada, Reno are all examples of this trend. These library makerspace pioneers are igniting a new wave of library transformation in the 21 st century.

\section{Makerspaces in Public Libraries}

Public libraries have always played a very important role in facilitating literacy and learning. By providing the general public with access to new technologies, public library makerspaces can help develop a new generation of workers who will build a stronger economy (Scott, 2012).

\section{Fayetteville Free Library}

The maker movement and maker culture were first embraced by public libraries. In 2011, the Fayetteville Free Library (FFL) in Fayetteville, New York opened the first modern library makerspace, the first of its kind in North America. While Lauren Smedley was working on a graduate school project paper at Syracuse University, she wrote a proposal about creating makerspaces in public libraries. The Fayetteville Free Library, interested in Ms. Smedley's 
makerspace idea, hired her to realize her dream at FFL. The new makerspace facility was called "Fab Lab", short for "Fabulous Laboratory" (McCue, 2011).

The Fab Lab focuses on fabrication tools and related resources and programs, wherein community members can come together to learn and use technologies and tools such as 3D printing, 3D scanning, laser cutting, vinyl cutting, sewing, crafting, hand tools, and electronics to make tangible objects. Besides the 2,500 square foot Fab Lab, the FFL has two additional makerspaces, the Creation Lab and Little Makers. Both facilities are approximately 250 square feet. The Creation Lab is a digital media lab focused on digital creation, which includes a wide range of digital media hardware and software such as video cameras, podcasting equipment, a green screen wall, and computers geared for media creation. The Little Makers is a play zone outfitted with toys, tools, and supplies including a DIY gallery wall and an "invention box" for children to learn, create, and build. A series of hands-on making and learning opportunities are offered through the FFL's maker programs, including family craft night, home repair, knitting, microcomputers and controllers, painting, robotics, sewing, quilting, 3D design and 3D printing. Before using the 3D printers, vinyl cutter or laser cutter independently, library patrons have to be certified by the library. They can book a 45-minute one-on-one certification appointment to receive basic safety and operational training. Makerspace usage is free at the FFL, but small fees are required for using certain materials. There are also various maker clubs organized by the FFL for community members to meet and socialize, including the Adult Robotics Club (Fayetteville Free Library, 2014).

Susan Considine, the FFL's Executive Director, sees the creation of makerspaces as encouraging a culture of innovation, and responding to the changing needs of its community (Doran, 2012). The FFL has introduced new opportunities for its community to learn, create and develop new ideas. Syracuse University's School of Information Studies professor David Lankes praised the FFL for setting a good example of what libraries can and should do in today's world (Doran, 2012). He also stated that libraries are increasingly becoming places of creation rather than places of consumption, and as such, they are helping the community get smarter.

\section{Westport Public Library}

Enis (2012) describes how, in 2012, the Westport Public Library (WPL) in Connecticut launched its makerspace and has served as a model for many other public libraries. One of the goals of the WPL's makerspace is to nurture the entrepreneurial spirit within the community. WPL's director Maxine Bleiweis wanted to see the new space become a place where people from the community could invent. She believes learning should be at every stage of a person's life and that the makerspace is a great venue to support the library's lifelong learning mission (Enis, 2012). The WPL allows its makerspace to evolve naturally. Instead of making a decision by itself, the library seeks community feedback to figure out next steps for its makerspace and works with the community to implement changes. The WPL demonstrates an interesting model; the library provides the makerspace framework but is not in charge of its future direction, and community members form its heart. The WPL hosted Connecticut's first Mini Maker Faire in April 2012. Nearly 2,200 people attended the event. It was the community that proposed the Mini Maker Faire idea. The creation of the WPL's makerspace was in response to the community's strong interest in the maker movement (Enis, 2012).

The WPL's makerspace has a unique structure, a large and open metal structure designed to look like the early airplane hangar where the Wright brothers built their plane (Coyne, 2013). The concept of flight is used as a metaphor for imagination in the makerspace. This area of the library provides cutting edge equipment such as 3D printers, and hosts various presentations and participatory workshops including topics such as robotics, arts, crafts, and intellectual property rights for inventors. The WPL is considering purchasing a programmable robot (Nao) for 
community members to learn coding, such as Python, to program the robot's behavior, voice, and movements. Community members can also schedule an appointment with a 3D printer coach. The majority of these coaches are volunteers from the community. In the WPL's makerspace, people of all ages are interacting and working together. In September 2013, a major grant from the Institute of Museum and Library Services (IMLS) was awarded to the WPL to enhance its makerspace, and provide hands-on and innovative learning experiences. As a result, the Maker-in-Residence program was established. Community members can work with the Maker-in-Residence and participate in projects such as digital quilt making, book-making, and creating Makey Makey musical instruments (Westport Public Library, 2014).

The WPL staff believes that they not only have the responsibility to improve the literacy levels of the community, but also to help community members develop new skills and knowledge to prepare for future jobs and new business opportunities. They believe entrepreneurship will be the key to America's economic prosperity in the 21st century (Westport Public Library, 2014).

\section{Chicago Public Library}

In 2009, the Chicago Public Library (CPL) launched a unique collaborative learning centre known as YOUmedia, the first dedicated space at the CPL for high school teens to learn digital media skills. YOUmedia consists of 5,500 square feet of space in the Harold Washington Library Center , the CPL's central library in downtown Chicago. The design of the YOUmedia space is based on a three-year ethnographic study of youth participation in the new media ecology, which concluded that young people are living and learning with digital media in three ways: "hanging out" with friends in social spaces, "messing around" with digital media, and "geeking out" to explore interests. YOUmedia provides a drop-in, out-of-school learning environment to teens. Based on teen interest, programs such as book discussions, low-tech maker crafts and recycled crafts were also created. All the programs in YOUmedia aim to inspire young people to create rather than consume. Every teen who uses the YOUmedia space is encouraged to learn based on self-interest and collaboration with peers (Chicago Public Library, 2014).

YOUmedia started as a learning space equipped with computers and digital media software. In the summer of 2013, the CPL used the IMLS grant they received to create a maker lab, an addition to YOUmedia, which has made the CPL a library leader in digital learning and collaborative creativity (Zupon, 2013).

The CPL's maker lab was created in partnership with the Museum of Science and Industry. It allows the general public to access cutting-edge technologies such as three 3D printers, two laser cutters, one milling machine, one vinyl cutter, and design software on a fleet of computers. Free workshops and drop-in demonstrations related to these technologies and tools are offered to the public (Chicago Public Library, 2014).

The IMLS grant only allowed the CPL to run the makerspace for 6 months, and the project was initially considered as a pilot. However, the CPL has received overwhelmingly positive feedback from patrons. With more than 30,000 visitors to the maker lab over the pilot period, it is certainly a successful initiative. It even attracted investment from major tech companies. Motorola Mobility provided funding to the CPL for running the maker lab for at least another year, offering more patrons hands-on experience in 3D software and advanced manufacturing technology. Google also offered 500 Finch Robots, which can be used to teach basic programming skills. Inventables, a Chicago based online hardware store for DIY manufacturing, donated 3D-carving machines. The central library runs a program that is intended to attract more women into the traditionally maledominated technology field. For many training technology sessions offered by the CPL, including how to use laser cutters and 3D printers, at least half of the participants are female. The makerspace 
has now become an integral part of the Library enabling the City of Chicago to become a major hub of advanced manufacturing over the next few decades (Rutkin, 2014).

Recently, CPL's maker lab established a connection between library patrons and the City Colleges of Chicago, which offers degrees in advanced manufacturing. College recruiters have offered several information sessions at the maker lab. This initiative provides a great opportunity for the library patrons who are interested in taking the skills they have learned from the maker lab programs a step further (Inklebarger, 2014).

\section{Ottawa Public Library}

Since 2013, Canadian libraries have started following the maker movement and creating their own makerspaces. As in the U.S., most library makerspaces in Canada are housed in public libraries.

The Ottawa Public Library (OPL) collaborated with the U.S. Embassy in Ottawa to open the first public makerspace in early 2014. The makerspace is called the Imagine Space, sponsored by the American Corners Program as a one-year pilot project. The goal of the Imagine Space is to provide public access to new technologies and tools, enhance hands-on learning experiences, and create a collaborative environment for exchanging ideas and sparking innovation. The U.S. Embassy contributed $\$ 58,000$ to purchase equipment, space preparation, and programming and the OPL provided the space and staff to manage the activities of the makerspace. The Imagine Space features a 3D printer, a laser cutter, a digital modeler, green screen, video and audio editing software, hand tools and electronics, and a wall-to-wall whiteboard. The equipment is bookable by OPL users. 3D printing and laser cutter certification classes, along with other maker events, are also offered to the community. Digital literacy, innovation, and entrepreneurship are the important elements that brought both the U.S. Embassy and OPL together to create the Imagine Space (Hendry, 2014).

\section{Toronto Public Library}

In February 2014, with $\$ 44,000$ in funding support from the Metcalf Foundation, the Toronto Public Library (TPL) opened a digital media lab known as the Digital Innovation Hub in its downtown Toronto Reference Library branch. This Hub has attracted considerable media attention. The creation of the Hub is based on a survey of the TPL community and consultations with other library makerspace pioneers, such as the Fayetteville Free Library. The Hub provides access to new technologies like 3D printers and scanners, Raspberry Pi computers, Arduino kits, Makey Makey kits, digital design workstations, high definition video cameras and audio mixers. One librarian and three design technicians currently staff the Hub, providing support and delivering various programs and services. The Hub is intended to be a space that fosters a community and collaborative learning. A variety of workshops have been offered to the public, ranging from 3D design to electronics and computer programming. The TPL has been building partnerships with local makerspaces and innovators including HackLab.TO, MakerKids, and Site 3 coLaboratory. These partnerships have helped the Hub host regular meetups, speaker events, and Innovators in Residence programs on topics such as robotics, wearable computing and art. With growing interest from the public, the Hub has become more and more appealing, even to patrons who rarely used or visited the TPL. To meet emerging needs of high schools, the TPL has developed a School Visits Program to help build digital literacy among students. Another Metcalf Foundation $\$ 50,000$ grant was received to strengthen the Hub's programming and expand its outreach to include youth in underemployed areas of the city (Gaitskell, 2014).

As the previous TPL City Librarian Jane Pyper stated, the Digital Innovation Hub is a space that inspires collaboration and creativity; it has broadened public access to emerging technologies and

will create immense opportunities for Torontonians to gain digital skills needed to be successful in 
today's digital world (Price, 2014). Since the launch of the first Digital Innovation Hub in the Toronto Reference Library, additional hubs have opened.

\section{Makerspaces in Academic Libraries}

The library makerspace trend started with public libraries, but more and more academic libraries are recognizing the benefit of makerspaces and their relevance to their strategic mission. This emerging trend can bring faculty and students together across disciplines, facilitate collaborative and hands-on learning, encourage knowledge sharing and creation, and help academic libraries adapt to the ever changing needs of their community.

In 2015, the Association of Research Libraries (ARL) conducted a survey of its 124 ARL member libraries to gather information for senior library staff to support decisions related to engagement with 3D printing, rapid fabrication and digitization technologies, and makerspaces in general. A Rapid Fabrication/Makerspace Services SPEC Kit (Association of Research Libraries, 2015) was developed based on the survey results. Among the 64 libraries that responded, offering makerspaces services appear to be of significant interest to ARL libraries, and a substantial majority of the responding libraries are currently engaged with makerspace service deployment. Respondent comments about the role of makerspace in their libraries are overwhelmingly positive: makerspaces are noted for fostering innovation, creativity, active learning, and scholarly communication etc. A number of respondents emphasized that the core competitive advantage of the library is not in providing hardware or simple physical space but in creating an environment that combines service, space, and expertise to foster individual and collaborative "investigation, interrogation, and learning through doing" (p. 13).

In the SPEC kit, ARL also outlined the strategic relevance of makerspaces to research libraries. First, makerspaces represent a unique use of library space. The assessment and renovation of libraries' use of space has been recognized as a current strategic issue for libraries in general. Second, libraries are increasingly engaging with data management. Digitization and fabrication technologies both make use of and produce research data. Third, fabrication is becoming increasingly important throughout the various stages of research lifecycles. There is a clear trend towards adoption in higher education generally. These technologies may be used early on as part of prototyping for research or to embed sensors for research data collection, or later on as part of analysis or research collaboration.

\section{DeLaMare Science and Engineering Library, University of Nevada in Reno}

The makerspace at DeLaMare Science and Engineering Library at the University of Nevada in Reno has been recognized as one of the most interesting academic makerspaces in America (Conway, 2014). This library service has benefited students and faculty from engineering, chemistry, theatre, art, anthropology and many other disciplines. The advancement of learning or research often demands going beyond pencil and paper. Increasingly, in order to complete their assignments, students are asked to produce posters, videos, tutorials, prototypes and models. The DeLaMare Library makerspace plays an important role in supporting student knowledge creation utilizing new technologies and tools. Furthermore, through collaboration with community organizations, a number of events have been hosted at the DeLaMare Library to promote hands-on learning. For example, Bridgewire Makerspace, a Nevada based organization, were invited to offer popular lock-picking workshops at the DeLaMare Library (Fisher, 2012).

The process of creating a makerspace at the DeLaMare Library was not straightforward. Despite state budget cuts and lack of space for the makerspace, Mr. Tod Colegrove, the Director of the DeLaMare Library, was able to secure an internal grant to acquire a 3D printer. Space for the 
makerspace was gained by moving little used print journals to an automated storage and retrieval system which freed up 18,000 square feet for people space. Savings was also realized by using surplus furniture from other university departments and the county school district. A white board was one of the students' most wanted items for collaborative work. Instead of paying $\$ 500$ for a 6by-4-foot white board, walls were painted with white board paint ( $\$ 500$ per 100 square feet). Several low cost but very useful electronics prototyping tool kits were also acquired, including items such as Arduino kits. Each tool kit cost less than an engineering or science book. In order to market the new space, 3D printers and scanners were placed in the entry lobby of the library for visibility. Within four months, more than 1,000 people had used the 3D printers and scanners. After the rollout of the makerspace and its programs and services, the number of library users increased dramatically (Good \& Borman, 2013).

The makerspace provides access to a wide range of digital fabrication tools such as 3D scanners, printers and a laser cutter as well as a collection of emerging augmented and virtual reality tools. Students are able to borrow physical computing devices (Arduino, Raspberry Pi and Makey Makey Kits). The library's research subject guides are used to provide information and guidance regarding services and technologies offered.

Makerspaces were not new to the university but the technologies and tools in existing makerspaces remained largely inaccessible to students and faculty outside of specific programs or research projects. Uniquely, DeLaMare Library's makerspace is completely open to everyone in the university for sharing technologies, tools, resources and expertise.

\section{North Carolina State University Libraries}

It didn't take much effort for North Carolina State University's (NCSU) new Hunt Library to sell its first 3D printing service to support NCSU's research and learning mission. A connection was made immediately for the researchers from NC State's Institute for Transportation Research and Education (ITRE) to apply the technology to turn their custom design, a map of a busy roundabout at Pullen Road and Stinson Drive, into a scale-model reality in a matter of days (NCSU Web, 2013). Students have also started to use the 3D printing and scanning equipment to build prototypes for their own projects.

Recently, the NCSU libraries have partnered with teams from across campus for a unique student sustainability challenge called make-a-thon, aiming to make an impact on campus sustainability. Over one weekend NC State students came up with smart and creative solutions such as KnowURshower and Trasher to help solve real-world sustainability issues. Students demonstrated what is possible when ingenuity meets library makerspace (Di Monte, 2016).

The success of Hunt Library's 3D printing service inspired the opening of a full-on makerspace, the Digital Media Lab, at the Hill Library in June 2015. David Woodbury, the head of user experience in NCSU who oversees the two makerspace libraries, pointed out that the new space is moving past the model of having students drop off files to be 3D printed by someone else and is now designed to give students a place to actually make things from start to finish (Brewer, 2015).

In June 2016, the NCSU Libraries' makerspace program won Special Libraries Association's Springshare Innovation in Libraries Award. In addition to the incredible work with 3D technology, wearable electronics, programming with Arduino \& Raspberry Pi, and milling with CNC machines, the Makerspace is also recognized for their unique work targeting women in STEM fields with their on-going speaker series, and by integrating their makerspace program into the curriculum of disciplines that aren't normally associated with technology (Springshare, 2016). 


\section{Digital Media Experience Lab, Ryerson University Library \& Archives}

In February 2015, the transformative new Ryerson University Student Learning Centre (SLC) opened in downtown Toronto as a place for students to collaborate, study, share ideas and learn beyond the traditional classroom. Located on the third floor of the SLC, the Isaac Olowolafe Digital Media Experience (DME) Lab is Ryerson's first dedicated makerspace, and was launched for students from all disciplines. As a new addition to the Ryerson University Library \& Archives (RULA), the DME is one of many RULA initiatives to exemplify the library of the 21 st century in which learning resources extend well beyond books.

As stated by Fangmin Wang, Head of Library Information Technology Services, "Traditionally, users talk about the serendipity of the stacks. Our DME Lab is a serendipity place in the digital age" (Braganza, 2015). With everything from 3D printers to virtual reality headsets, the DME provides students with access to a wide range of emerging technologies for experimentation and exploration. Students can attend a variety of workshops in the DME and get one-on-one instruction from DME student staff in the use of advanced media creation tools. Although the initial plan of the DME was as a lab to help students learn digital media tools such as Adobe Photoshop, it soon expanded its scope after recognizing the rise of the library makerspace and its importance to RULA's future.

The DME not only encourages do-it-yourself but also learn-it-together, through its peer-to-peer learning service model supported by a full-time coordinator and 7 part-time student staff who come from a wide range of academic backgrounds. The DME provides an experiential learning environment that enables digital skills development while it disseminates knowledge. The DME also promotes cross-disciplinary collaboration at Ryerson while inspiring digital innovation in other institutions. The projects created in the DME have been exhibited at the Royal Ontario Museum and Toronto International Film Festival's digiPlaySpace. Many Ryerson faculty members have also started using the DME to integrate emerging technology into their curriculum. For example, the Department of Architecture worked with the DME to develop student digital skills including the use of Oculus Virtual Reality headsets to visualize 3D model design assignments.

Librarians and library staff have also started participating in DME programming and activities. Library staff had a well-established knitting group that met regularly to work on group and individual projects. When the DME acquired a knitting machine, staff from the library were eager to learn about this new technology. The acquisition of this machine and launch of the DME's "Knit Happens" weekly drop-in has not only integrated library staff, it has also broadened the reach of the DME to students who may not have considered coming into the space.

Other library staff have been involved with the DME as a result of establishing its technology lending program. Staff from several units in the library and a Master's practicum student worked to develop the policies, procedures and workflow for circulating DME equipment using the library's integrated library system. Once this service was operationalized, Lunch and Learn sessions were held to familiarize all library staff with the service.

\section{MADLab, Gerstein Science Information Centre, University of Toronto}

The MADLab at the Gerstein Science Information Centre is a student-centric facility open to University of Toronto students, staff and faculty. Unlike many other academic library makerspaces, it runs on a self-service rather than full-service model. The lab is open from 9-5 each weekday, but access is only through self-serve pre-arranged times. There are two main foci of the space, mobile app development and 3D scanning and printing. Students who wish to use the 3D facilities must follow a multi-step process of certification, requesting a print time, having their project approved, then getting a key for the space and printing their project. The certification process involves 
learning about the types of printers in the lab (by viewing videos and reading user manuals), attending safety training in the lab and passing a knowledge test (University of Toronto, 2016).

This self-service operating model allows the maker lab to run without additional staff. However, students have to book prints at least 48 hours in advance and the lack of immediate mentoring and technical support can be constraining.

\section{Other University Makerspaces (University of Victoria and University of Toronto)}

Opened in September 2012, what differentiates Canada's first makerspace, the University of Victoria Libraries' MLab is that it's anchored in blending humanities research lab with a collaborative makerspace. "With research priority areas in physical computing, digital fabrication, and multi-site exhibits, the MLab intersects culture criticism with experimental prototyping and electronics" (University of Victoria, 2016).

The Critical Making Lab at the Faculty of Information (iSchool), University of Toronto is another example of a university makerspace. The lab provides tools, materials and training for building devices such as wearable computers, RFID systems, ubiquitous computing networks, and other physical computing technologies, and is only open to students and faculty in the iSchool. The critical making lab organizes its efforts around the making of material objects. Its ultimate goal is to perform a practice-based engagement with the pragmatic and theoretical issues around information and information technology through the sharing of results and ongoing critical analysis of materials, designs, and outcomes with the lab participants (University of Toronto, 2016).

\section{Other Makerspaces (Mobile Makerspaces)}

It's obvious that not every library is equipped with adequate funding, tools, resources, or staffing to run a local makerspace. Libraries have been thinking out of the box to create alternative makerspaces within limited budgets. Mobile makerspaces have gained popularity due to their flexibility and ease of creation. The concept of mobile makerspaces originated from the earliest book wagon project operated by staff in Washington County, Maryland in 1905 (Goldstein, 1961). When patrons couldn't come to a brick and mortar library, the bookmobile worked just as well.

Space, location and accessibility are just a few reasons why a library may think of going mobile. Moorefield-Lang (2015) did comprehensive research through case studies of six librarians and educators who made the decision to go mobile with a makerspace. In her research, two makerspaces were in fully built trucks, one was carried in a library van, two makerspaces were transported in school buses, and one traveled across campus in a cart. Moorefield-Lang's six mobile makerspaces included:

- Monticello High School in Charlottesville (USA)'s "Makers on the Move" program which allowed them to visit their younger peers at the nearby elementary and middle schools to engage in maker activities.

- Europe's first mobile library fablab, called Frysklab Mobile, which allows library staff to visit small villages, schools and libraries, or other countries easily. One Frysklab event of note was the MakerTour 2015 that included twelve stops in eight different countries across Europe.

- Chicago Public Library took another step in 2014 to roll out mini Makerlabs. Mini Makerlabs were established in three separate library branches across the Chicago area. The Mini MakerLab funneled users to the central branch makerspace.

- Elon University's MobileMaker which used a rolling cart to establish a pop-up makerspace in the residential hall. 
- The DHMakerBus, Canada's first mobile makerspace, was created by London Public Library, Ontario. The MakerBus not only opens up the community to the world of making, it also provides teachers and librarians with professional development opportunities.

- SparkTruck, managed by the d.school at Standford University, began in a rental truck in February 2012 and soon became a nation-wide maker experience. The team travels across the USA offering pop-up maker opportunities at libraries, schools, community centers, and more. Some of the popular projects included vibrobots, which are small vibrating robots that run on a small battery and motor, as well as stamp creation using the laser cutter.

Since Moorefield-Lang's study, many more mobile makerspaces have emerged. Mobile makerspaces are an inexpensive way to promote maker culture and get community members excited about learning through making. However, there are also limitations to this approach. Through implementing the MobileMaker in Elson, Gierdowski \& Reis (2015) discovered that mobility and security were mutually exclusive; with the mobile design chosen, greater mobility was sacrificed to achieve greater security. They also discovered that the level of access was reduced due to staffing limitations. As a result, they are currently discussing the possibility of finding a permanent location.

\section{CONCLUSIONS}

Our research has indicated that the adoption of makerspaces within libraries has been growing. The impact of DIY has led to new ways of learning through making and creating. By offering technologies and equipment such as 3D printers and virtual reality tools, libraries are creating an inclusive learning environment for students who do not have equal access to new technology resources and support. As learning itself becomes more distributed, students can learn anywhere and in any flexible space. Libraries need to actively think about ways to incorporate the making concept as they are developing their learning spaces and programs.

Our literature review has shown that makerspaces in public libraries have been well received by the public library user community. They have become or are becoming strategic priorities for public libraries seeking to reposition themselves in the digital age. As pointed out in the Horizon Report 2016, makerspaces in academic libraries have become increasingly popular as libraries respond to changes in curriculum and to the societal need for active learning, cross-disciplinary approaches and creativity. Being open and accessible is the key to building a successful makerspace in both public and academic libraries.

However, makerspaces have been approached differently by public and academic libraries. Public libraries in general aim to foster lifelong learning and community engagement through programs that appeal to a broad demographic with widely varying interests. Their maker programs, such as crafts nights and Lego workshops, are informative, entertaining and suitable for all ages. Academic library makerspaces, on the other hand, tend to be tied to the educational mission of the university and pedagogical needs of the curriculum. The makerspace programs in academic libraries are developed to help students acquire knowledge and skills in emerging technologies and support creative curriculum development. An academic library makerspace is the perfect place for students to interact, collaborate and create as they gain practical knowledge and digital skill sets.

Although more and more libraries are interested in creating a makerspace, many factors need to be considered including sustainability, staffing, funding, ongoing maintenance of the technology, operational model and future directions of the space. The success of a library makerspace is not just about providing technologies such as $3 \mathrm{D}$ printers but about building a great community that embraces the maker movement and advocates for learning by making or doing. At Ryerson, many 
academic programs require hand-on skills and are career-oriented. The Library's Digital Media Experience Lab has met the needs of students in supporting their projects either for their school work or extracurricular activities. For some libraries, having mobile maker programs with portable tools and technologies may be an effective way to reach out their community. For others, makerspaces are more sustainable if library staff are trained in an educational role and assist with daily operations. Libraries need to identify their strengths and constraints, and create makerspaces that are unique and meet their needs and priorities.

We have learned that many makerspaces in academic libraries have been used to support students in the context of experiential learning; however, little consideration has been given to how to support researchers and faculty members especially for those who are from non-engineering or technology related programs. For many researchers, emerging technologies have started to become research methodologies. For example, virtual reality has been used to create digital reconstructions of historical monuments for visualization. 3D printing has been explored as an innovative way of engaging with primary materials in the arts and humanities. For faculty members and researchers who have limited access to lab facilities, equipment and technical expertise, library makerspaces could intensify their research outcomes as well as contribute to pedagogical innovation. Our next step is to investigate how academic libraries can establish a new business model that leverages the makerspace concept to support faculty wishing to integrate innovative technologies in their research and curriculum. We would like to see a library research and innovation collaboratory that truly facilitates new knowledge creation and exchange, disseminates cutting-edge research and helps establish exemplary teaching and learning practices.

\section{References}

Anderson, C. (2013). The maker movement: Tangible goods emerge from ones and zeros. Wired, 21(5), 106.

Association of Research Libraries. (2015, September). SPEC kit 348: Rapid fabrication/makerspace services. Retrieved from http://publications.arl.org/Rapid-Fabrication-Makerspace-Services-SPEC-Kit-348/

Bagley, C. (2012, December 20). What is a makerspace? Creativity in the library. ALA TechSource. Retrieved from http://www.alatechsource.org/blog/2012/12/what-is-a-makerspace-creativity-in-the-library.html

Barba, R. (2014, March 21). GE opens a pop-up 3D printing lab in downtown DC. Retrieved from http://tech.co/gegarages-dc-2014-03

Braganza, C. (2015). Smart space: New building transforms how students learn. Ryerson University Magazine, Summer 2015. Retrieved from http://ryerson.ca/content/dam/alumni/news/magazine/backissues/2015/summer15.pdf

Brewer, B. (2015). Making it in the academic world. American Libraries, 46 (9/10), 20-21.

Chicago Public Library. (2014). YOUmedia. Retrieved from http://www.chipublib.org/youmedia/

Conway, A. (2014, July 17). University recognized as one of the most interesting makerspaces in America. Nevada Today. Retrieved from http://www.unr.edu/nevada-today/news/2014/makerspace

Coyne, M. (2013, July 17). Westport Library celebrates Makerspace. The Hour Online. Retrieved from http://www.thehour.com/westport/article/Westport-Library-celebrates-Makerspace-8210048.php

Di Monte, L. (2016, June 22). NCSU Libraries: 'Making' an impact on campus sustainability. Retrieved from https://www.imls.gov/news-events/upnext-blog/2016/06/ncsu-libraries-making-impact-campus-sustainability

Doran, E. (2012, July 18). Fayetteville Library offers cutting-edge technology for patrons. Retrieved from http://webcache.googleusercontent.com/search?q=cache:j9t4mnb4dJUJ:www.syracuse.com/news/index.ssf/2 $\underline{012 / 07 / \text { fay.html+\&cd=1\&hl=en \&ct=clnk\&gl=ca }}$

Dougherty, D. (2012). The maker movement. Innovations: Technology, Governance, Globalization, 7(3), 11-14. Retrieved from http://www.mitpressjournals.org/doi/pdf/10.1162/INOV_a_00135 
Dougherty, D. (2013). The maker mindset. In Honey, M., \& Kanter, D. (eds.). Design, Make, Play: Growing the Next Generation of STEM Innovators. (pp. 7-11). New York, NY: Routledge.

Educause. (2013). 7 Things you should know about ... Makerspaces. Retrieved from http://net.educause.edu/ir/library/pdf/ELI7095.pdf

Enis, M. (2012, July 3). Westport Library unveils new maker space. The Digital Shift. Retrieved from http://www.thedigitalshift.com/2012/07/ux/westport-library-unveils-new-maker-space/

Fayetteville Free Library. (2014). 21 Questions about FFL makerspaces. Retrieved from https://www.fflib.org/make/makerspace-faqs

Fisher, E. (2012, November 28). Makerspaces move into academic libraries. ACRL TechConnect Blog. Retrieved from http://acrl.ala.org/techconnect/?p=2340

Fleming, L. (2014, March 24). If you let them build it, they will learn. Retrieved from http://worlds-oflearning.com/2014/03/24/if-you-let-them-build-it-they-will-learn/

Gaitskell, V. (2014, April). The modern library. PrintAction, 14-40. Retrieved from http://issuu.com/printaction/docs/printaction_april2014

Gierdowski, D., \& Reis, D. (2015). The MobileMaker: An experiment with a mobile makerspace. Library Hi Tech, 33(4), 480-496. doi:10.1108/LHT-06-2015-0067

Good, T., \& Borman, L. D. (2013). Manufacturing MAKER SPACES. American Libraries, 44(1/2), 44-49.

Hendry, C. (2014, April 12). Nepean Centrepointe Library unveils 'Imagine space: an American corner'. Ottawa Citizen. Retrieved from http://ottawacitizen.com/news/local-news/nepean-centrepointe-library-unveilsimagine-space-an-american-corner

Inklebarger, T. (2014, June 5). Long live the maker lab. American Libraries. Retrieved from http://www.americanlibrariesmagazine.org/blog/long-live-maker-lab

Kalil, T. \& Miller, J. (2014, June 4). The first-ever White House maker faire: Celebrating a nation of makers. Retrieved from http://www.whitehouse.gov/blog/2014/06/04/first-ever-white-house-maker-faire-celebrating-nation$\underline{\text { makers }}$

Lay, S. (2014, February 7). Maker day allows students to showcase creativity. Retrieved from http://statenews.com/article/2014/07/msu-library-hosts-maker-day

Library as Incubator Project. (2012, May 13). A WAPL recap. Retrieved from http://www.libraryasincubatorproject.org/?p=4594

Maker Ed. (2013). Makerspace playbook school edition. Retrieved from http://makerspace.com/wpcontent/uploads/2013/02/MakerspacePlaybook-Feb2013.pdf

Manitoba Crafts Museum and Library. (2014). Canada's only museum of craft - Our story. Retrieved from http://www.mcml.ca/about-mcml/

McCue, T. (2011, November 15). First public library to create a maker space. Retrieved from http://www.forbes.com/sites/tjmccue/2011/11/15/first-public-library-to-create-a-maker-space/

Moorefield-Lang, H. M. (2015). When makerspaces go mobile: Case studies of transportable maker locations. Library Hi Tech, 33(4), 462-471. doi:10.1108/LHT-06-2015-0061

Morin, B. (2013, May 2). What is the maker movement and why should you care? Retrieved from http://www.huffingtonpost.com/brit-morin/what-is-the-maker-movemen_b_3201977.html

North Carolina State University. (2013, April). Hunt Library: Create reality. Retrieved from https://www.ncsu.edu/huntlibrary/create/

New Media Consortium. (2014). The NMC horizon report 2014 higher education edition. Retrieved from http://cdn.nmc.org/media/2014-nmc-horizon-report-he-EN-SC.pdf

New Media Consortium. (2015). The NMC horizon report 2015 higher education edition. Retrieved from http://cdn.nmc.org/media/2015-nmc-horizon-report-HE-EN.pdf

New Media Consortium. (2016). The NMC horizon report 2016 higher education edition. Retrieved from http://cdn.nmc.org/media/2016-nmc-horizon-report-he-EN.pdf

Price, G. (2014, February 13). Roundup: New makerspaces, media labs, and innovation hubs open (or coming soon) inside three Canadian public libraries. Library Journal. Retrieved from 
http://www.infodocket.com/2014/02/13/roundup-new-makerspaces-media-labs-and-innovation-hubs-foundinside-three-canadian-public-libraries/

Rebuilding Together Central Ohio. (2014). Our programs. Retrieved from http://www.rtcentralohio.org/about-us/ourprogram/

Rutkin, A. (2014, July 17). Books out, 3D printers in for reinvented US libraries. New Scientist. Retrieved from http://www.newscientist.com/article/mg22329784.000-books-out-3d-printers-in-for-reinvented-uslibraries.html?full=true\#.U-OhlkgRb_s

Scott, H. (2012, November 11). Making the case for a public library makerspace. Public Libraries Online. Retrieved from http://publiclibrariesonline.org/2012/11/making-the-case-for-a-public-library-makerspace/

Sharples, M., McAndrew, P., Weller, M., Ferguson, R., Fitzgerald, E., Histr, T., \& Gaved, M. (2013, September). Innovating pedagogy 2013: Open University innovation report 2. Retrieved from http://www.open.ac.uk/iet/main/sites/www.open.ac.uk.iet.main/files/files/ecms/webcontent/Innovating_Pedagogy_report_2013.pdf

Springshare Blog. (2016, July 1). NCSU's makerspace program wins SLA's Springshare innovation award. Retrieved from http://blog.springshare.com/2016/07/01/ncsus-makerspace-program-wins-slas-springshare-innovation$\underline{\text { award } /}$

Tashjian, K. (2014, March 12). Learn about the makerspace movement. Retrieved from http://allaccessri.org/2014/03/12/learn-about-the-makerspace-movement/

University of Toronto. (2016). MADLab. Retrieved from http://mobile.utoronto.ca/madlab

University of Toronto. (2016). Critical Making Lab. Retrieved from http://criticalmaking.com/

Uinversity of Victoria. (2016). About the MLab. Retrieved from http://maker.uvic.ca/about/

Westport Public Library. (2014). Makerspace. Retrieved from http://westportlibrary.org/services/maker-space

Zupon, P. (2013, April 9). Presenting maker spaces: Libraries are truly more than books. Retrieved from http://blogs.wayne.edu/turninginformationintoknowledge/2013/04/09/presenting-maker-spaces-libraries-aretruly-more-than-books/

\section{About the authors}

Fangmin Wang is the Head of Ryerson University's Library Information Technology Services. He has been responsible for many technology innovations to enhance library services. Fangmin was instrumental in creating the Digital Media Experience Lab in Ryerson's Student Learning Centre, which has served as an innovation hub for students to learn new technologies. Fangmin obtained his MLIS degree from McGill University.

Weina Wang is the Borrowing and Lending Services System Librarian at Ryerson University Library. Being a digital media and technology advocate, she has led staff through a series of technological changes in order to respond to the 21 st century patron needs. Weina obtained her M.Sc. degree in Information Systems from the University of Sheffield, UK.

Sally Wilson is the Web Services Librarian at Ryerson University, Toronto. She has led many projects including systems migrations and large-scale web projects. She obtained her MLS degree from the University of Toronto.

Namir Ahmed is the Coordinator for Ryerson Library's Digital Media Experience Lab. He has a background in Archaeology and Digital Media. Namir is an MA candidate at Western University. 